\title{
Efficacy of Alpha-1 Adrenergic Blockers in the Management of Benign Prostatic Hyperplasia
}

\author{
Sudhir Sabharwal ${ }^{1}$, Narita Jamwal ${ }^{2}$ \\ ${ }^{1}$ Neurosurgeon, Govt. Hospital, Gandhinagar, Jammu, ${ }^{2}$ Gynaecologist, ASCOMS, Jammu India.
}

\section{Abstract}

Background: Benign prostatic hyperplasia (BPH), the most common benign tumour in men. The present study was planned to assess quantitatively the symptom improvement with Terazosin and with Prazosin in patients with symptomatic BPH. Subjects and Methods: The present study was conducted on 30 patients. The patients were studied under two subgroups, allotted at random, each had 15 patients. The sub group A patients received prazosin GITS tablet and sub group B patients received Terazosin. The urinary symptom scores were measured by using AUA symptom index, comprising seven equally weighted questions addressing the severity of urinary symptoms. Results: The pre drug therapy symptom score in group A \& B were comparable and there was no significant difference between the two subgroup of patients $(\mathrm{P}>$.05). On comparison of improvement in AUA score between Group A and Group B, no significant difference was found (P > .05). There was also no significant difference in improvement of obstructive and irritative subscores between the two sub groups. Group B patients had significant reduction of the post void residual urine following treatment. Conclusion: Prazosin GITS is an effective formulation of Prazosin, which ensures single daily use of this agent. Prazosin GITS and Terazosin are equally effective in improving the bothersome symptoms of $\mathrm{BPH}$ in symptomatic patients.

Keywords: Benign prostatic hyperplasia, Prazosin, Terazosin.

Corresponding Author: Dr. Narita Jamwal, Gynaecologist, ASCOMS, Jammu India.

Received: March 2019

Accepted: April 2019

\section{Introduction}

Benign prostatic hyperplasia (BPH), the most common benign tumour in men, is responsible for urinary symptoms in men over the age of 50 years. The proportion of men with a negative feeling of well being is higher in men with BPH than in men who do not have BPH. These men have a higher level of bothersomeness attributed to urinary symptoms and more interference in selected daily living activities caused by urinary dysfunction. ${ }^{[1]}$

With the development of pathologically identifiable benign prostatic hyperplasia, the weight significantly increases with time and averages $33 \pm 16 \mathrm{gm}$. Only 4 percent of the prostate in men over 70 years old reach sizes greater than $100 \mathrm{gm} .{ }^{[2]}$ The growth of benign prostatic hyperplasia is initiated probably before the patient is 30 years old. The early phase of benign prostatic hyperplasia growth (men between 31 and 50 years old) is characterized by a doubling time for the tumour weight of 4.5 years. In the mid phase of benign prostatic hyperplasia (men between 51 and 70 years old) the doubling time is 10 years and increases to more than 100 years in patients beyond 70 years old's. ${ }^{[3]}$ The major target of pharmacologic therapy is $\alpha-1$ adrenergic receptor in bladder neck and prostatic capsule, as the tension of prostatic smooth muscle is mediated by $\alpha-1$ adrenoreceptor. ${ }^{[4]}$ Many selective $\alpha$-blockers are available but the selective $\alpha-1$ blockers, such as prazosin and terazosin produce fewer side effects. ${ }^{[5]}$ The medical management by $\alpha-1$ blockers in the treatment of BPH aims at the correction of dynamic component and thereby the improvement of prostatism. Therapy with $\alpha-1$ blockers Prazosin and Terazosin has been found to be safe in patients of BPH. ${ }^{[6]}$ The present study was planned to assess quantitatively the symptom improvement with Terazosin and with Prazosin in patients with symptomatic BPH.

\section{Subjects and Methods}

The present study was conducted in the department of Urology, Postgraduate Institute of Medical education \& Research, Chandigarh. A total of 30 patients were included in this study. The study protocol was approved from institute. All were informed regarding the study and written consent was obtained.

The patients were studied under two subgroups, allotted at random, each had 15 patients. The sub group A patients received prazosin GITS tablet and sub group B patients received Terazosin.

All patients were evaluated clinically (history, physical examination, digital rectal examination). Investigations included haemogram and routine urine examination, renal function tests such as blood urea/serum creatinine, urine culture and sensitivity, $\mathrm{x}$ ray KUB to rule out stone disease, 
ultrasonography (trans abdominal and TRUS) of kidney, ureter, bladder and prostate with special emphasis on prostate volume, echotexture and residual urine. Prostatic specific antigen level was determined in all patients as a screening test for carcinoma prostate.

Before starting drug therapy, their urinary symptom scores were measured by using AUA symptom index, comprising seven equally weighted questions addressing the severity of urinary symptoms. All the patients were interviewed by the same interviewer (resident himself) as most patients, who participated in this study were not educated enough to understand and interpret the questions correctly and equally. For the purpose of study the questionnaires 1,4,7 were assigned as irritative and 2,3,5,6 as obstructive subscore.

Severity of symptom score was graded as AUA Score, 0 - 7 mild, 8 - 19 moderate, 19 - 35 severe. All patients received medications as a single daily dose at bed time. Subgroup A patients were given Prazosin GITS (Minipress XL, Pfizer) $2.5 \mathrm{mg}$ for the initial one week, then $5 \mathrm{mg}$ for the next 7 weeks. All these patients were explained that they may note the presence of ghost tablet of Minipress XL in the stool as this outer shell remain undigested in the intestine.Subgroup B patients were given Terazosin (Hytrin ${ }^{\circledR}$ Abbott Laboratories) in the following schedule Day $1-3: 1 \mathrm{mg}$, Day 4 - $7: 2 \mathrm{mg}$ and Day 8 till completion of study (8 weeks) : $5 \mathrm{mg}$.

The patients were instructed to report to the out patient clinic if there is any adverse reaction to drugs e.g. asthenia, syncopal episodes etc. The patients were seen in the out patient clinic on day 3 and day 7 after starting the therapy and again at 4 weeks and 8 weeks. During their visit at 4 weeks and 8 weeks, their symptomatic improvement and AUA symptom score were evaluated. Post void residual urine was re-evaluated by ultrasonography at the end of therapy. The degree of improvement of symptoms was graded as Slight - Reduction of AUA score upto 10\%, Moderate - Reduction of AUA score in range of 10 - 30\% and Marked - Reduction of AUA score more than 30\%. The change in score before and after surgery was tested by using Wilcoxon signed rank test within a group. The Wilcoxon Mann - Whitney test was applied to compare the efficacy of drugs between two groups.

\section{Results}

[Table 1] shows that the age of patients ranged from 50-79 years. Majority of patients were in the range of 55-74 years.

\begin{tabular}{|l|l|l|}
\hline Table 1: Age wise distribution of patients. \\
\hline Age (Years) & Group A & Group B \\
\hline $50-54$ & 2 & - \\
\hline $55-59$ & 5 & 3 \\
\hline $60-64$ & 5 & 4 \\
\hline $65-69$ & - & 3 \\
\hline $70-74$ & 3 & 4 \\
\hline $75-79$ & - & 1 \\
\hline
\end{tabular}

Table 2: Pre-drug therapy symptom severity (AUA symptom score)

\begin{tabular}{|l|l|l|l|l|}
\hline AUA Score & \multicolumn{2}{|l|}{ No. of Patients } & $\%$ age \\
\cline { 2 - 5 } & Group A & Group B & A & B \\
\hline $\begin{array}{l}\text { Moderate }(8- \\
19)\end{array}$ & 9 & 8 & $60 \%$ & $53 \%$ \\
\hline $\begin{array}{l}\text { Severe (19 - } \\
35)\end{array}$ & 6 & 7 & $40 \%$ & $47 \%$ \\
\hline
\end{tabular}

[Table 2] shows that $60 \%$ in group A and $53 \%$ in group B had moderate AUA score while $40 \%$ in group A and $47 \%$ in group B had severe AUA score.

Table 3: Comparison of AUA score

\begin{tabular}{|l|l|l|l|}
\hline & $\begin{array}{l}\text { Mean Obstructive } \\
\text { score }\end{array}$ & $\begin{array}{l}\text { Mean Irritative } \\
\text { score }\end{array}$ & $\begin{array}{l}\text { Mean AUA } \\
\text { Score }\end{array}$ \\
\hline Group A & 8.73 & 8.13 & 16.87 \\
\hline Group B & 8.00 & 8.47 & 16.47 \\
\hline
\end{tabular}

[Table 3] shows that the total AUA score of the patients in Group A ranged from 8 to 31 with a mean of $16.87 \pm 7.93$. The total AUA score of patients in Group B ranged from 8 to 28 with a mean of $16.47 \pm 7.13$. The difference in AUA Score as well as obstructive and irritative subscores between Group A and B was statistically not significant.

Table 4: Symptom severity and prostate volume
\begin{tabular}{|l|l|l|l|l|}
\hline $\begin{array}{l}\text { Prostate } \\
\text { Volume on } \\
\text { USG }\end{array}$ & $\begin{array}{l}\text { No. of } \\
\text { patients in } \\
\text { both the } \\
\text { groups }\end{array}$ & $\begin{array}{l}\text { AUA } \\
\text { Score } \\
\text { (Mean) }\end{array}$ & $\begin{array}{l}\text { Obstr. } \\
\text { Score } \\
\text { (Mean) }\end{array}$ & $\begin{array}{l}\text { Irrit. } \\
\text { Score } \\
\text { Mean) }\end{array}$ \\
\hline $20-40 \mathrm{gm}$ & 20 & 16.45 & 8.15 & 8.30 \\
\hline $40-80 \mathrm{gm}$ & 10 & 17.10 & 8.80 & 8.30 \\
\hline
\end{tabular}

[Table 4] shows that the prostate volume measured by transrectal ultrasonography in Group A ranged from 20-80 $\mathrm{cc}$ with a mean of $37.8 \mathrm{cc}$. The prostate volume in Group B ranged from 20 to $74 \mathrm{cc}$ with a mean of $37.8 \mathrm{cc}$. No significant change in AUA score was observed when prostate volume increased from $20 \mathrm{gm}$ to $80 \mathrm{gm}$.

\begin{tabular}{|l|l|l|l|}
\hline Table 5: Symptom improvement after drug therapy in group A \\
\hline & $\begin{array}{l}\text { AUA Score } \\
\text { before } \\
\text { therapy }\end{array}$ & $\begin{array}{l}\text { AUA Score } \\
\text { After therapy }\end{array}$ & Palue \\
\hline Total & 16.8 & 9.07 & $\mathrm{P}<.01$ \\
\hline Obstructive & 8.73 & 4.47 & $\mathrm{P}<.01$ \\
\hline Irritative & 8.13 & 4.60 & $\mathrm{P}<.01$ \\
\hline
\end{tabular}

[Table 5] shows that in group A the mean AUA score was 16.8, which decreased to 9.07 after giving Minipress XL. The change is statistically significant. $(\mathrm{P}<.01)$. The mean obstructive score was 8.73 , which decreased to 4.47 after therapy. The change is statistically significant $(\mathrm{P}<.01)$. The mean irritative score was 8.13 , which decreased to the mean value of 4.60 . The change is also statistically significant $(\mathrm{P}$ $<.01)$. The mean residual urine before drug therapy was $43.33 \mathrm{ml}$, which decreased to a mean value of $35.00 \mathrm{ml}$ post drug therapy. This change was statistically not significant $(\mathrm{P}$ $>0.05$ ). 
Table 6: Symptom improvement after drug therapy in group B

\begin{tabular}{|l|l|l|l|}
\hline & $\begin{array}{l}\text { AUA Score } \\
\text { before } \\
\text { therapy }\end{array}$ & $\begin{array}{l}\text { AUA Score } \\
\text { After therapy }\end{array}$ & P value \\
\hline Total & 16.47 & 8.67 & $\mathrm{P}<.01$ \\
\hline Obstructive & 8.0 & 4.20 & $\mathrm{P}<.01$ \\
\hline Irritative & 8.47 & 4.47 & $\mathrm{P}<.01$ \\
\hline
\end{tabular}

[Table 6] shows that in group B, the mean AUA Score was 16.47, which decreased to the mean value of 8.67 after giving Hytrin. The change observed was statistically significant $(\mathrm{P}<.01)$. The mean obstructive score was 8.00 , which decreased to mean value of 4.20 after drug therapy. This change observed was also statistically significant $(\mathrm{P}<$ $.01)$. The mean irritative score was 8.47 , which decreased to a mean value of 4.47 after drug therapy. The change observed was also statistically significant $(\mathrm{P}<.01)$. The mean residual urine was $80 \mathrm{ml}$, which decreased to a mean value of 18.50 after drug therapy. The observed change was statistically significant $(\mathrm{P}<.01)$.

\begin{tabular}{|l|l|l|l|l|}
\hline Table 7: Comparison of values in both groups \\
\hline & $\begin{array}{l}\text { Group A } \\
\text { Mean } \\
\text { Value }\end{array}$ & $\begin{array}{l}\text { Group B } \\
\text { Mean } \\
\text { Value }\end{array}$ & Z-Value & P-Value \\
\hline $\begin{array}{l}\text { AUA Score } \\
\text { (Pre) }\end{array}$ & 16.87 & 16.47 & -0.124 & $\mathrm{P}>05$ \\
\hline $\begin{array}{l}\text { Obstr. Score } \\
\text { (Pre) }\end{array}$ & 8.73 & 8.00 & -0.311 & $\mathrm{P}>05$ \\
\hline Irr. Score (Pre) & 8.13 & 8.47 & 0.021 & $\mathrm{P}>.05$ \\
\hline $\begin{array}{l}\text { AUA Score } \\
\text { (Post) }\end{array}$ & 9.07 & 8.67 & -0.021 & $\mathrm{P}>05$ \\
\hline Irr. Score (Post) & 4.60 & 4.47 & -0.311 & $\mathrm{P}>05$ \\
\hline $\begin{array}{l}\text { AUA } \\
\text { Improvement }\end{array}$ & 7.80 & 7.80 & -0.166 & $\mathrm{P}>05$ \\
\hline $\begin{array}{l}\text { Obstr. } \\
\text { Improvement }\end{array}$ & 4.27 & 3.80 & 0.726 & $\mathrm{P}>05$ \\
\hline $\begin{array}{l}\text { Irr. } \\
\text { Improvement }\end{array}$ & 3.53 & 4.00 & 0.311 & $\mathrm{P}>05$ \\
\hline $\begin{array}{l}\text { Residual Urine } \\
\text { (Pre) }\end{array}$ & 43.33 & 80.00 & 1.313 & $\mathrm{P}>05$ \\
\hline $\begin{array}{l}\text { Residual Urine } \\
\text { change }\end{array}$ & 8.33 & 61.50 & 1.973 & $\mathrm{P}>050$ \\
\hline
\end{tabular}

[Table 7] shows that the pre drug therapy symptom score in group A \& B were comparable and there was no significant difference between the two subgroup of patients $(\mathrm{P}>.05)$. On comparison of improvement in AUA score between Group A and Group B, no significant difference was found $(\mathrm{P}>$.05). There was also no significant difference in improvement of obstructive and irritative subscores between the two sub groups. Group B patients had significant reduction of the post void residual urine,following treatment. These patients had a higher residual urine (mean of $80 \mathrm{ml}$ ), which was reduced to a mean of $18.50 \mathrm{ml}$. In Group A, the pre drug therapy mean residual urine volume was $43.33 \mathrm{ml}$. which decreased to a mean of $35.00 \mathrm{ml}$. This reduction was statistically not significant.

[Figure 1] shows that the marked improvement (> 30\%) was observed in 10 patients of Group B and 11 patients of Group A. Moderate improvement (10 - 30\%) was observed in 4 patients of group B and two patients of Group A. Slight improvement $(<10 \%)$ was observed in one patient in Group $\mathrm{B}$ and two patients in Group A. These patients were offered surgical treatment.

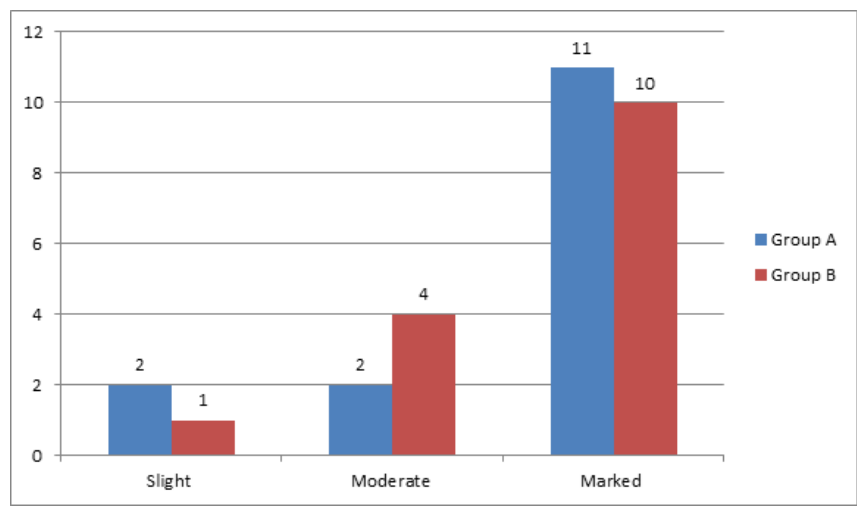

Figure 1: Degree of improvement in both the groups

\section{Discussion}

The bladder neck and prostate are richly innervated by sympathetic nerve fibres through the pelvic plexus. This sympathetic activity is mediated predominantly by $\alpha-1$ adenoreceptors. Based on this principle several workers have demonstrated significant beneficial outcome with $\alpha-1$ blocker therapy on patients with symptomatic BPH. ${ }^{[7]}$ The present study was undertaken to evaluate the efficacy of $\alpha-1$ blocker therapy in patients of sympatomatic BPH in our population.

In our study, 30 patients were included in two sub groups of 15 patients each. The study was completed at 8 weeks following drug therapy with $\alpha-1$ antagonists. The 15 patients of Group A received Prazosin $2.5 \mathrm{mg}$ for 1 week and then 5 $\mathrm{mg}$ (as a sustained release preparation - Minipress XL) as a single daily bed time dose continuously for next 7 weeks. All patients completed the protocol of treatment and none had any significant side effects. At the completion of the study protocol the mean AUA score decreased from 16.8 to 9.7. In other words the mean AUA symptom score reduced by $57.7 \%$, which is statistically significant $(\mathrm{P}<.01)$. The decrease in mean obstructive and mean irritative subscores was also statistically significant. The mean residual urine volume decreased from $43.3 \mathrm{ml}$ to $35 \mathrm{ml}$ an improvement of $19 \%$, which is statistically not significant.

Two patients in Group A had associated hypertension. One patient was diabetic controlled on oral hypoglycemics and one patient had associated asthma. The hypertensive patient had a dual benefit of the drug therapy. The drug was well tolerated by all other normotensive patients.

In a study by Hedlund et ${ }^{\left[{ }^{[8]}\right.}{ }^{[8}$ in 20 men with $\mathrm{BPH}$. Prazosin was administered in the dose of $4 \mathrm{mg}$ daily. It was a crossover study with placebo. In this study the effect of prazosin treatment was significant in terms of improving the obstructive symptoms and residual volume $(\mathrm{P}<.05)$. However, the improvement in irritative score was not statistically significant. In the placebo group - the effect was equal for irritative and obstructive symptoms but it was not statistically significant. The improvement in obstructive 
subscore in this study was comparable to the results of our study.

In a study conducted by Kirby et al, ${ }^{[9]}$ Prazosin was given in the dose of $4 \mathrm{mg}$ daily (2 $\mathrm{mg} \mathrm{BD}$ ). In this study a statistically significant difference in reduction of urinary frequency was observed in comparison to placebo $(\mathrm{P}<$ 0.01). The improvement in nocturia was also observed in this study $(\mathrm{P}<0.05)$. The observation in our study is in agreement with this study.

In both, the studies, no side effects was noted, except one patient in study by Caine, ${ }^{[10]}$ had transitory dizziness during the first two days of maximum dose of prazosin $(4 \mathrm{mg})$. The Prazosin used in our study is a long acting and sustained release preparation and all patients were given the drug only at bed time. No patient in our study had any significant side effects.

The 15 patients of Group B in our study received Terazosin $1 \mathrm{mg}$ for day 1-3, $2 \mathrm{mg}$ for day 4-7 and $5 \mathrm{mg}$ from day 8 till completion of study i.e. 8 weeks. All patients in this group completed the study protocol and none had any significant side effect.

The mean AUA symptom score was improved by $52.6 \%$. The obstructive subscore improved by $52.5 \%$ and the irritative subscore improved by $52.7 \%$. All these findings are statistically significant $(\mathrm{P}<.01)$. The mean residual urine volume decreased from $80 \mathrm{ml}$ to $18.5 \mathrm{ml}$, an improvement of $77 \%$, which is statistically significant ( $\mathrm{P}$ $<.01)$.

In a study by Lepor et al, ${ }^{[11]}$ the improvement in obstructive and irritative symptom scores was 63 and $35 \%$ respectively after giving Terazosin upto $5 \mathrm{mg}$. The improvement was assessed by Boyarsky Symptom Score. The improvement in obstructive scores was dose dependent and did not reach a plateau at the dose of $5 \mathrm{mg}$. No significant side effects were observed in this study.

In another study by Lepor et al, ${ }^{[11]}$ a 24 months follow up was done with Terazosin dosage of $5 \mathrm{mg}$. The obstructive and irritative symptom scores had decreased by $63 \%$ and $35 \%$ respectively after 2 months of Terazosin Therapy. These improvements in obstructive and irritative symptom scores were maintained throughout the two year follow up. The improvement in obstructive subscores of our study is in agreement with the above study.

On comparing the results of both the groups A \& B in our study, it was found that both Terazosin and Prazosin GITS are equally effective in causing improvement of symptomatic prostatism. Marked subjective improvement and marked (> 30\%) reduction of AUA symptom score was noted in $73.3 \%$ patients of group $A$ and $66.6 \%$ patients of Group B. Both these $\alpha-1$ blocking agents are safe and well tolerated during the period of study and no patient in any of the study group had significant side effects due to these drugs.

Although Prazosin is short acting as compared to Terazosin, the special formulation of Prazosin (Prazosin GITS) ensures slow and sustained release of the drug in the alimentary tract thereby enabling us to prescribe the drug as a single daily dose.

In both groups A \& B patients the symptom score recorded at the completion of 4 weeks and 8 weeks of study protocol were the same i.e. no further improvement in their symptoms noted once the improvement reached a plateau with the prescribed dosage of $5 \mathrm{mg}$ Terazosin/Prazosin. It may be mentioned here that the dose of $5 \mathrm{mg}$ Terazosin/Prazosin GITS was reached by the second week in all our study patients.

The AUA symptom questionnaire has been widely accepted as a tool for measuring the severity of symptoms in patients of symptomatic BPH. ${ }^{[13]}$ In our study the same questionnaire has been utilized for evaluating the symptoms. However this questionnaire is approved for self administration, but as the study population in our study was not educated enough to understand and interpret the question equally- the patients were interviewed by the same interviewer for maintaining uniformity of the study.

\section{Conclusion}

Medical therapy with adrenergic blocking agents like Prazosin GITS and Terazosin is an effective treatment for patients with symptomatic BPH. $73.3 \%$ patients of Group A and $66.6 \%$ patients of Group B in this study had marked (>30\%) reduction of AUA symptom score following 8 weeks of therapy. Both these drugs are well tolerated by our study population as no patient in this study group complained of any significant side effect. Prazosin GITS is an effective formulation of Prazosin, which ensures single daily use of this agent. Prazosin GITS and Terazosin are equally effective in improving the bothersome symptoms of $\mathrm{BPH}$ in symptomatic patients.

\section{References}

1. Madsen FA, Reginald C and Bruskewitz RC. Clinical manifestations of benign prostatic hyperplasia. Urol. Clin. North Am.1995; 22(2):29198.

2. Shapiro E and Lepor H. Pathophysiology of clinical benign prostatic hyperplasia. Urol.Clin.North Am.1995; 22(2):285-90.

3. Bartsch G, Muller HR, Oberholzer M, et al. Light microscopic stereological analysis of the normal human prostate and of benign prostatic hyperplasia. J. Urol. 1979; 122:487-91.

4. Shapiro E, Hartano V and Lepor H. Quantifying the smooth muscle content of prostate using double immuno enzymatic staining and colour assisted image analysis. J. Uro1.1992; 147:1167-70.

5. Barry MJ and Michael P0. The development and clinical utility of symptom, scores. Urol. Clin. North Am. 1995;22(2):299-307.

6. Caine M. The present role of alpha-adrenergic blockers in the treatment of benign prostatic hypertrophy. J. Uro1.1986;136:1-6.

7. Lepor H. Alpha blockade for treatment of benign prostatic hyperplasia. Urol. Clin. North Am.1995; 22(2):375-85.

8. Hedlund H., Andersson KE and EK.A. Effects of Prazosin in patients with benign prostatic obstruction. J. Uro1.1983;130:275-78.

9. Kirby RS, Coppinger SWC, Corcoran MO, et al. Prazosin in the treatment of prostatic obstruction. Br J Urol 1987;60:136-42.

10. Caine M. Reflections on alpha blockade therapy for benign prostatic hyperplasia. Br J Urol 1995;75:265-70.

11. Lepor H, Maloney GK and Sunshine H. A dose titration study evaluating Terazosin a selective once a day al - blocker for the treatment of symptomatic BPH. J Urol 1990; 144:1393-98.

12. Chapple CR, Stott M, Abrams PH, et al. A 12 week placebo controlled double blind study of Prazosin in the treatment of prostatic obstruction due to BPH. Br J Urol 1992; 70:285-94.

13. Tsang KK and Garraway WM. Impact of benign prostatic hyperplasia on general well being of men. The Prostate,1993;23:1-7. 
Copyright: (C) the author(s), 2019. It is an open-access article distributed under the terms of the Creative Commons Attribution License (CC BY 4.0), which permits authors to retain ownership of the copyright for their content, and allow anyone to download, reuse, reprint, modify, distribute and/or copy the content as long as the original authors and source are cited.

How to cite this article: Sabharwal S, Jamwal N. Efficacy of Alpha-1 Adrenergic Blockers in the Management of Benign Prostatic Hyperplasia. Asian J. Med. Res. 2019;8(2):SG01-SG05.

DOI: dx.doi.org/10.21276/ajmr.2019.8.2.SG1

Source of Support: Nil, Conflict of Interest: None declared. 